\title{
Kajian Permintaan Perjalanan Penumpang dalam Rangka Penyediaan Prasarana Sarana Transportasi Umum di Bali
}

\author{
Putu Hermawati', I G M Oka Aryawan², I Ketut Sutapa³, I Made Anom Santiana4 \\ 1.2.3.4 Jurusan Teknik Sipil, Politeknik Negeri Bali \\ Email: ${ }^{1}$ hermawati@pnb.ac.id, ${ }^{2}$ okaaryawan@pnb.ac.id, ${ }^{3}$ ketutsutapa@pnb.ac.id, \\ ${ }^{4}$ madeanomsantiana@pnb.ac.id
}

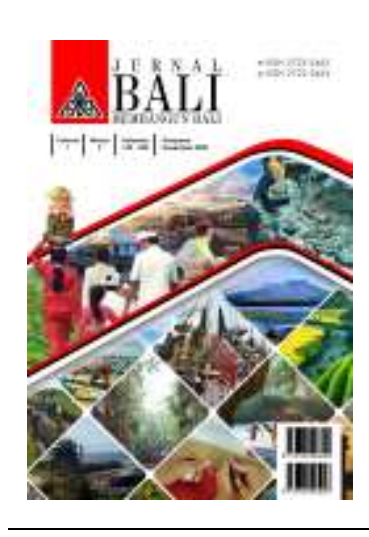

Sejarah Artikel

Diterima pada 17 Juli 2020

Direvisi pada 19 Juli 2020

Disetujui pada 12 Agustus 2020

\section{Abstrak}

Tujuan: Untuk mengembangkan kebijakan transportasi yang lebih komprehensif di Bali, penelitian ini perlu dilakukan.

Metode Penelitian: Pengumpulan data dilakukan dengan melakukan survei berbasis kuesioner.

Temuan: Perjalanan distribusi internal menunjukkan produksi perjalanan tertinggi dari Denpasar dan Kuta, sekitar $24,93 \%$ dan $11,75 \%$, sedangkan atraksi perjalanan terbesar juga ke Denpasar dan Kuta, yaitu $13,76 \%$ dan $16,73 \%$ dari total jumlah perjalanan orang per hari. Distribusi perjalanan eksternal menunjukkan bahwa sebagian besar orang yang keluar masuk Bali melalui Bandara Ngurah Rai dan Pelabuhan Gilimanuk. Pemilihan modal menunjukkan bahwa yang paling banyak digunakan adalah sepeda motor $85,40 \%$, mobil $10,27 \%$, truk $3,60 \%$ dan angkutan umum $0,73 \%$. Perkiraan generasi perjalanan dan daya tarik memiliki tingkat pertumbuhan $5,812 \%$ / tahun.

Implikasi: Perlu diantisipasi untuk mengembangkan moda alternatif baru berdasarkan teknologi dari Denpasar ke semua kabupaten, seperti Kereta / LRT / ART dan transportasi feri, yang disepakati oleh $83,56 \%$ dan $89,33 \%$ dari orang-orang.

Kata kunci: transportasi umum, Provinsi Bali, kuesioner, produksi perjalanan, atraksi perjalanan, tingkat pertumbuhan.

\section{Abstract}

Purpose: To develop a more comprehensive transportation policy in Bali, this research needs to be conducted.

Research methods: Data collection is done by conducting questionnaire-based surveys.

Findings: The internal distribution trips shows the highest trip production from Denpasar and Kuta, about $24.93 \%$ and $11.75 \%$, while the largest trip attraction are also to Denpasar and Kuta, which are $13.76 \%$ and $16.73 \%$ of the total number of people trips per day. The distribution of external trips shows that most people going in and out of Bali are through Ngurah Rai Airport and Gilimanuk Port. The modal selection shows that the most used are $85.40 \%$ motorcycle, $10.27 \%$ car, $3.60 \%$ trucks and $0.73 \%$ public transportation. The forecasts of trip generation and attraction have growth rates of $5.812 \% / y e a r$.

Implications: It needs anticipated to develop new alternative modes based on technology from Denpasar to all districts, such as Train/LRT/ART and ferry transportation, which was agreed by $83.56 \%$ and $89.33 \%$ of the people.

Keywords: pubic transportation, Bali Province, questionnaire, trip production, trip attraction, growth rates.

\section{PENDAHULUAN}

Dalam pembangunan transportasi, pemerintah baik Pemerintah Pusat, Provinsi maupun Pemerintah Kabupaten/Kota mempunyai peranan sesuai 
cakupan kewenangannya masing-masing, yaitu berkewajiban untuk menyusun rencana dan merumuskan kebijakan, mengendalikan dan mengawasi perwujudan transportasi. Salah satu kewajiban dimaksud adalah melaksanakan pembangunan prasarana dan sarana transportasi, dengan prioritas daerahdaerah yang belum berkembang, untuk peningkatan ekonomi masyarakat.

Untuk menghadapi era industrialisasi 4.0 dan dalam mendukung program Nawa Cita Presiden RI, maka Gubernur Bali periode 2018-2023 Dr. Ir. Wayan Koster, M.M. juga telah menetapkan visi yang dijabarkan ke dalam 22 misi, di mana misi ke-18 tersebut mencerminkan komitmen Pemprov Bali dalam transportasi yaitu : "Meningkatkan pembangunan infrastruktur (darat, laut dan udara) secara terintegrasi serta konektivitas antar wilayah untuk mendukung pembangunan perekonomian serta akses dan mutu pelayanan publik di Bali".

Pengguna transportasi umum di Bali cenderung kian menurun, di mana hasil survei Public Transport Study (Th. 2005) menunjukkan pengguna angkutan umum hanya $5 \%$, yang cenderung menurun terus hingga saat ini penggunaan angkutan umum darat diperkirakan kurang dari $1 \%$. Transportasi darat didominasi secara signifikan oleh angkutan pribadi khususnya sepeda motor dan mobil. Di Bali terjadi ketidakseimbangan antara pertumbuhan kendaraan bermotor 5,396\% per tahun dan prasarana jalan 0,01\% per tahun (BPS, 2019), menimbulkan permasalahan kemacetan lalu lintas dan pencemaran udara, serta berdampak pada kerugian masyarakat seperti menurunnya tingkat kualitas udara, waktu tempuh yang lama dan peningkatan biaya operasional kendaraan.

Guna menyusun kebijakan-kebijakan transportasi di Bali yang lebih komprehensif maka perlu diketahui permintaan perjalanan penumpang di tiaptiap wilayah Kabupaten/Kota beserta proyeksinya untuk jangka panjang guna pengembangan transportasi yang terkoneksi dan terintegrasi. Untuk itu dilakukan penelitian "Kajian permintaan perjalanan penumpang dalam rangka penyediaan prasarana sarana transportasi umum di Bali". Tujuan penelitian ini adalah sebagai berikut (1) Menganalisis dan memproyeksikan permintaan perjalanan angkutan umum di tiap-tiap wilayah Kabupaten/Kota di Bali. (2) Membuat alternative solusi penyediaan prasarana dan sarana untuk pengembangan transportasi umum yang terintegrasi. 


\section{METODE PENELITIAN}

\section{Pengumpulan Data}

Data yang dikumpulkan dapat digolongkan menjadi data primer dan data sekunder. Data sekunder didapatkan dari instansi terkait (Badan Pusat Statistik Provinsi Bali, Dinas Perhubungan Provinsi/Kota/Kabupaten di Bali, Organda, Pawiba) berupa data eksisting ketersediaan prasarana dan sarana angkutan umum (Supply) dan dari laporan penelitian-penelitian sebelumnya. Pengumpulan data primer dengan melaksanakan survei untuk memperoleh data-data di lapangan, seperti data perjalanan dengan melakukan survei asal tujuan pergerakan dan persepsi pengguna angkutan umum melalui survei berbasis kuisioner.

\section{Rancangan Kegiatan Penelitian}

Rancangan kegiatan penelitian yang dilakukan, secara garis besar dapat dilihat pada bagan alir seperti pada Gambar 1.

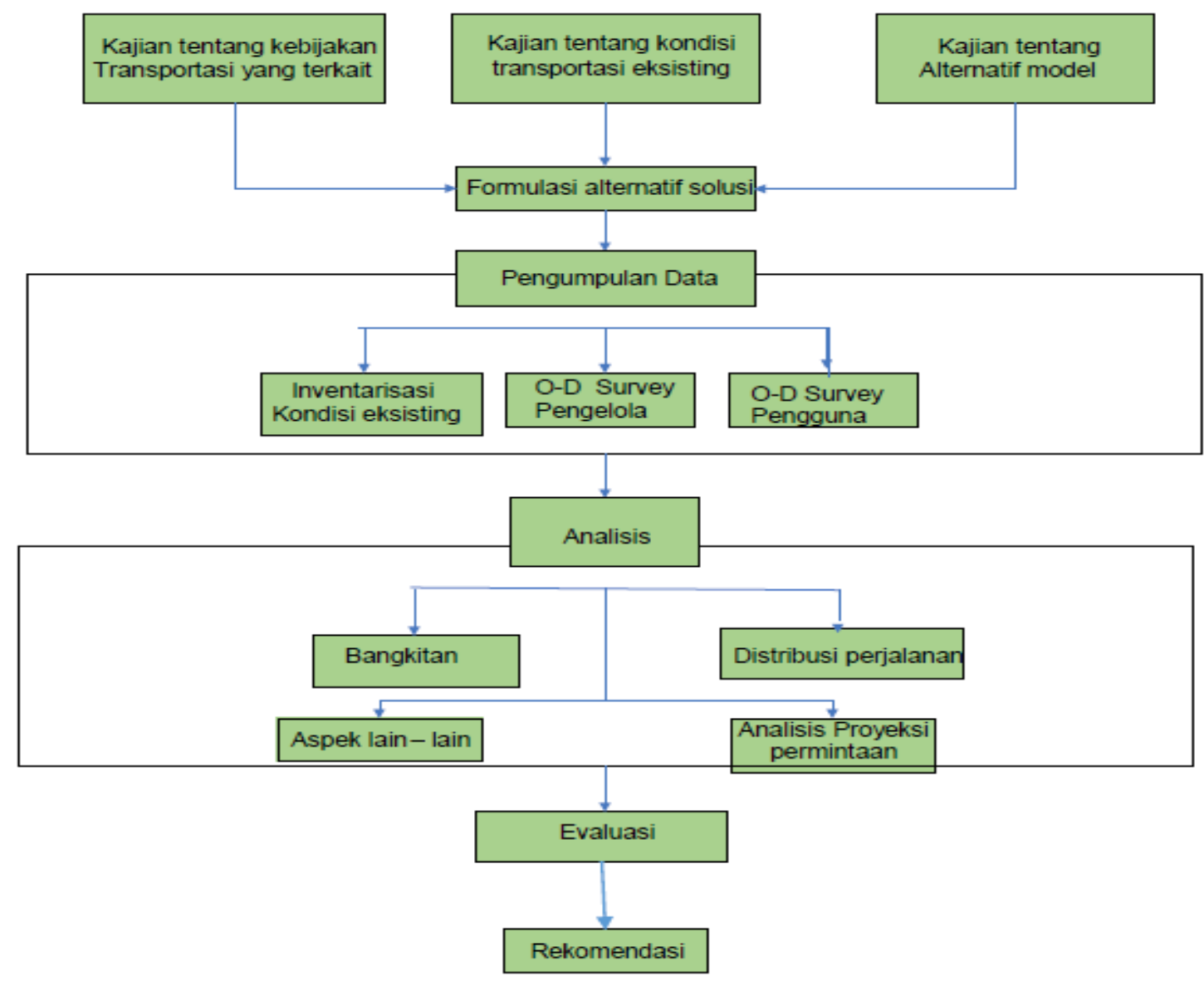

Gambar 1. Bagan Alir Kegiatan Penelitian 


\section{Analisis Data dan Permodelan}

Metode analisis data dan pemodelan adalah dengan pendekatan statistik kuantitatif dan kualitatif deskriptif. Analisis peramalan permintaan perjalanan (Demand) untuk mengetahui bangkitan perjalanan angkutan umum saat ini dan proyeksinya pada tahun mendatang, dilakukan dengan faktor pertumbuhan. Nilai faktor pertumbuhan dapat dihitung melalui beberapa alternatif yaitu pertumbuhan kepemilikan kendaraan bermotor, pertumbuhan lalu lintas harian rata-rata (LHR) dan pertumbuhan volume kendaraan. Pembuatan rekomendasi untuk keseimbangan Supply \& Demand dan pengembangan angkutan umum terintegrasi dengan pendekatan kualitatif.

\section{HASIL DAN PEMBAHASAN}

\section{Gambaran Kondisi Transportasi Bali}

Kondisi transportasi di Bali ditunjukkan dengan gambaran jumlah kendaraan bermotor dalam lima tahun terakhir meningkat rata-rata 6,41\% per tahun atau kepemilikan kendaraan bermotor bertambah rata-rata sebanyak 218.495 unit setiap tahun atau bertambah 599 unit setiap hari, sedangkan peningkatan prasarana jalan rata-rata $1,83 \%$ per tahun, menunjukkan nyata ketidakseimbangan antara penyediaan prasarana jalan dengan tingkat pertumbuhan kepemilikan kendaraan. Tingkat motorisasi di Bali juga cukup tinggi yaitu 1,45 dan 1,29 di Denpasar dan Badung.

Mobilitas barang dan jasa keluar-masuk Bali dapat dicapai melalui Pelabuhan Penyeberangan, Pelabuhan Laut dan Bandar Udara. Berdasarkan data tahun 2018, jumlah penumpang keluar-masuk Bali sebanyak 40.115.106 orang terdiri dari penumpang datang 19.606 .505 orang atau 48,88 \% dan penumpang berangkat 20.508 .601 orang atau $51,12 \%$ dengan peningkatan dalam lima tahun terakhir rata-rata $7,79 \%$ pertahun.

\section{Evaluasi Distribusi Perjalanan Eksisting}

Evaluasi kondisi eksisting, meliputi evaluasi aspek permintaan perjalanan (travel demand), aspek bangkitan perjalanan dan pola pergerakan (distribusi perjalanan) penumpang angkutan umum. Berdasarkan Tabel 1, Propinsi Bali sebagai wilayah perencanaan dibagi dalam 27 zona asal dan 
tujuan, di mana masing-masing kabupaten/Kota diasumsikan memiliki 3 zona. Tingkat aksesibilitas dari suatu zona dipengaruhi oleh besarnya aktivitas yang tersebar disekitar zona tersebut dan kondisi prasarana sarana transportasi yang menghubungkannya. Analisis aksesibilitas dilakukan terhadap 4 (empat) lokasi aktivitas yaitu pasar dan pertokoan, sekolah, terminal dan tempat wisata. Sesuai analisis di Tabel 1 tersebut diketahui, aksesibilitas ke aktivitas pasar dan pertokoan, 81,48 \% memiliki aksesibilitas yang tinggi, artinya sebagian besar masyarakat tidak memliki kendala dalam hal menuju ke fasilitas pasar dan pertokoan atau Mall. Agak berbeda dengan aksesibilitas zona menuju terminal, $85,19 \%$ memiliki aksesibiltas menengah, artinya masyarakat penumpang masih memiliki kendala menuju fasilitas terminal. Untuk aksesibilitas zona ke aktivitas sekolah memiliki akssesibilitas menengah dan tinggi yang berimbang yaitu $59,26 \%$ dan $40,74 \%$, juga untuk ke tempat wisata memiliki akssesibilitas menengah dan tinggi yang juga berimbang yaitu $48,15 \%$ dan $51,85 \%$.

Tabel 1. Rekapitulasi Kondisi Aksesibilitas Masing-Masing Zona

\begin{tabular}{clcccc}
\hline \multirow{2}{*}{$\begin{array}{c}\text { Kode } \\
\text { Zona }\end{array}$} & \multicolumn{1}{c}{ Area } & \multicolumn{4}{c}{ Prosentase Posisi Aksesibilitas } \\
\cline { 3 - 6 } & Pertokar \& & $\begin{array}{c}\text { Sekolah } \\
\text { (\%) }\end{array}$ & $\begin{array}{c}\text { Terminal } \\
\text { (\%) }\end{array}$ & $\begin{array}{c}\text { Tempat } \\
\text { Wisata (\%) }\end{array}$ \\
\hline 1 & Kota Denpasar & 30 & 27.00 & 23 & 20.00 \\
\hline 2 & Ubung & 28 & 17.00 & 30 & 25.00 \\
\hline 3 & Sanur & 30 & 17.00 & 17 & 36.00 \\
\hline 4 & Dalung & 30 & 30.00 & 17 & 23.00 \\
\hline 5 & Kuta & 28 & 17.00 & 16 & 39.00 \\
6 & Nusa Dua & 30 & 17.00 & 16 & 37.00 \\
\hline 7 & Kota Gianyar & 37 & 17.00 & 16 & 30.00 \\
8 & Ubud & 25 & 17.00 & 16 & 42.00 \\
\hline 9 & Batu Bulan & 30 & 17.00 & 16 & 37.00 \\
\hline 10 & Batur & 16 & 20.00 & 20 & 44.00 \\
\hline 11 & Kota Bangli & 30 & 35.00 & 18 & 17.00 \\
\hline 12 & Dawan & 25 & 30.00 & 25 & 20.00 \\
\hline 13 & Kota Klungkung & 35 & 28.00 & 20 & 17.00 \\
\hline 14 & Pasar Kidul & 35 & 20.00 & 20 & 25.00 \\
\hline 15 & Gunaksa & 18 & 28.00 & 20 & 34.00 \\
\hline 16 & Gilimanuk & 18 & 20.00 & 38 & 24.00 \\
\hline 17 & Kota Negara & 30 & 30.00 & 20 & 20.00 \\
\hline 18 & Melaya & 28.00 & 34 & 18.00 \\
\hline 19 & Kota Tabanan & 20 & 30.00 & 20 & 20.00 \\
\hline 20 & Bedugul & 30 & 18.00 & 17 & 45.00 \\
\hline 21 & Tanah Lot & 20 & 18.00 & 20 & 42.00 \\
\hline & & 25 & & & \\
\hline
\end{tabular}




\begin{tabular}{llcccc}
\hline 22 & Karangasem Kota & 40 & 20.00 & 20 & 20.00 \\
23 & Padang Bai & 25 & 18.00 & 20 & 42.00 \\
24 & Candidasa & 25 & 28.00 & 18 & 34.00 \\
$25 \quad$ Kota Singaraja & 35 & 30.00 & 18 & 17.00 \\
$26 \quad$ Lovina & 25 & 18.00 & 20 & 42.00 \\
$27 \quad$ Seririt & 30 & 20.00 & 30 & 20.00 \\
Jumlah Area & & & & \\
Rendah 0\%-15\% & 0 & 0 & 0 & 0 \\
Menengah 16\%-25\% & 5 & 16 & 23 & 13 \\
Aksesibiltas Tinggi > 25\% & 22 & 11 & 4 & 14 \\
$\begin{array}{l}\text { Persentase (\%) } \\
\text { Rendah }\end{array}$ & - & - & - & - \\
Menengah & 18.52 & 59.26 & 85.19 & 48.15 \\
\hline Tinggi & 81.48 & 40.74 & 14.81 & 51.85 \\
Total & $\mathbf{1 0 0 , 0 0}$ & $\mathbf{1 0 0 , 0 0}$ & $\mathbf{1 0 0 , 0 0}$ & $\mathbf{1 0 0 , 0 0}$ \\
\hline
\end{tabular}

Tipe-tipe perjalanan yang sering dilakukan masyarakat di Bali adalah perjalanan ke tempat kerja, merupakan maksud perjalanan dengan proporsi terbesar, yang selanjutnya diikuti oleh perjalanan ke sekolah, rekreasi dan perjalanan sosial lainnya seperti yang ditampilkan dalam Tabel 2.

Tabel 2. Bangkitan Perjalanan Berdasarkan Maksud Perjalanan

\begin{tabular}{|lc}
\hline Maksud Perjalanan & Persentase (\%) \\
\hline Bekerja (Bisnis) & 37,92 \\
Sekolah & 27,92 \\
Wisata (Rekreasi) & 20,83 \\
Belanja (Sosial) & 13,33 \\
\hline
\end{tabular}

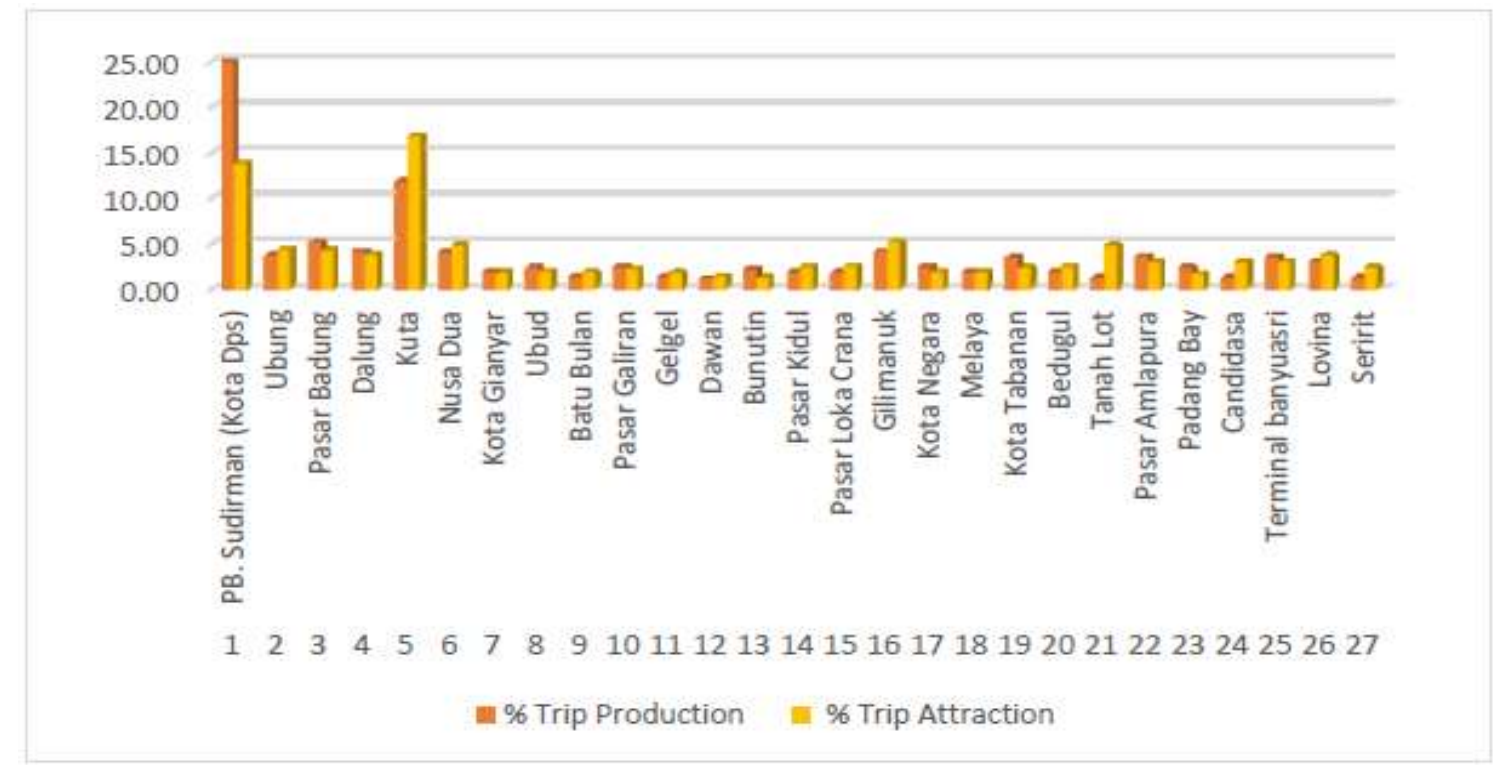

Gambar 2. Diagram Distribusi Perjalanan tiap Zona di Provinsi Bali 
Distribusi perjalanan masing-masing Zona di Provinsi Bali dapat dilihat pada Gambar 2, menunjukkan bahwa produksi perjalanan terbanyak terdapat pada zona 1 (Kota Denpasar) dan zona 5 (Kuta) yaitu sebesar 24,93\% dan $11,75 \%$. Sedangkan tarikan perjalanan terbesar juga terdapat pada zona 1 (Kota Denpasar) dan zona 5 (Kuta) yaitu sebesar $13,76 \%$ dan $16,73 \%$ dari total jumlah perjalanan orang perhari di Bali.

\section{Proyeksi Permintaan Perjalanan}

Analisis model produksi perjalanan perhari (internal dan external trip) dicoba menggunakan tiga variabel bebas, yaitu: jumlah penduduk, PDRB, pertumbuhan kendaraan bermotor. Dari hasil proses regresi SPSS didapatkan persamaan linier sebagai berikut:

$$
Y_{\text {prodc }}=6392890.775+1.576 . \times 3 \longrightarrow R 2=\quad \longrightarrow, 928
$$

Di mana : $Y_{\text {prodc }}=$ nilai trip production

$\mathrm{X} 3=$ pertumbuhan kendaraan bermotor

Selanjutnya model Tarikan Perjalanan Perhari (internal dan external trip) dicoba menggunakan tiga variabel bebas, yaitu: perkembangan jumlah wisatawan mancanegara, fasilitas terminal penumpang angkutan jalan dan jumlah hotel. Dari hasil proses regresi SPSS didapatkan persamaan linier sebagai berikut :

$$
Y_{\text {attract }}=2323257.803+0.383 . \mathrm{X} 1 \longrightarrow R 2=0,703
$$

Di mana : $Y_{\text {attract }}=$ nilai trip attraction

$\mathrm{X} 1=$ perkembangan jumlah wisatawan mancanegara

Dari uji koefisien determinasi $(R 2)$ model didapatkan bahwa nilai $R 2$ sudah mendekati 1 yaitu $(R 2=0.928)$ untuk trip production dan $(R 2=0,703)$ untuk trip attraction yang menunjukkan bahwa hubungan antara variabel tidak bebas dengan variabel bebasnya bersifat linear atau kuat. 
Besarnya bangkitan dan tarikan perjalanan pada tahun dasar (tahun 2019) dilakukan dengan memasukkan data variabel bebas pada model persamaan regresi tersebut di atas, sehingga diperoleh hasil produksi perjalanan perhari seperti terlihat pada Tabel 3.

Tabel 3. Bangkitan dan Tarikan Perjalanan Orang Perhari Tahun 2019.

\begin{tabular}{|c|c|c|c|c|c|}
\hline $\begin{array}{l}\text { Kode } \\
\text { Zona }\end{array}$ & Area & $\begin{array}{c}\text { Trip } \\
\text { Production } \\
\text { (Org/hari) }\end{array}$ & Prosentase & $\begin{array}{c}\text { Trip } \\
\text { Attraction } \\
\text { (Org/hari) }\end{array}$ & Prosentase \\
\hline \multicolumn{6}{|c|}{ ZONA INTERNAL } \\
\hline 1 & DENPASAR & $1,353,577$ & 32.64 & 947,504 & 22.66 \\
\hline 2 & BADUNG & 844,680 & 20.37 & $1,098,084$ & 26.26 \\
\hline 3 & GIANYAR & 432,012 & 10.42 & 475,213 & 11.36 \\
\hline 4 & KLUNGKUNG & 128,680 & 3.10 & 141,548 & 3.38 \\
\hline 5 & BANGLI & 114,413 & 2.76 & 125,854 & 3.01 \\
\hline 6 & JEMBRANA & 200,932 & 4.85 & 221,025 & 5.28 \\
\hline 7 & TABANAN & 404,804 & 9.76 & 445,284 & 10.65 \\
\hline 8 & KARANGASEM & 190,108 & 4.58 & 209,119 & 5.00 \\
\hline 9 & BULELENG & 426,958 & 10.30 & 469,654 & 11.23 \\
\hline \multicolumn{6}{|c|}{ ZONA EXTERNAL } \\
\hline 10 & GILIMANUK & 18,524 & 0.45 & 17,814 & 0.43 \\
\hline 11 & BENOA & 1,081 & 0.03 & 1,072 & 0.03 \\
\hline 12 & $\begin{array}{l}\text { PADANG BAI } \\
\text { BANDARA }\end{array}$ & 1,997 & 0.05 & 1,888 & 0.05 \\
\hline 13 & $\begin{array}{l}\text { NGURAH RAI } \\
\text { Total } \\
\text { Perjalanan } \\
\text { (org/hari) }\end{array}$ & $4,146,901$ & 100.00 & $4,182,130$ & 100.00 \\
\hline
\end{tabular}

Berdasarkan moda yang digunakan tercatat bahwa kendaraan roda dua memegang komposisi yang besar, yaitu sebesar 85,40 \%. Gambar 3 berikut menjelaskan penggunaan moda di Propinsi Bali. 


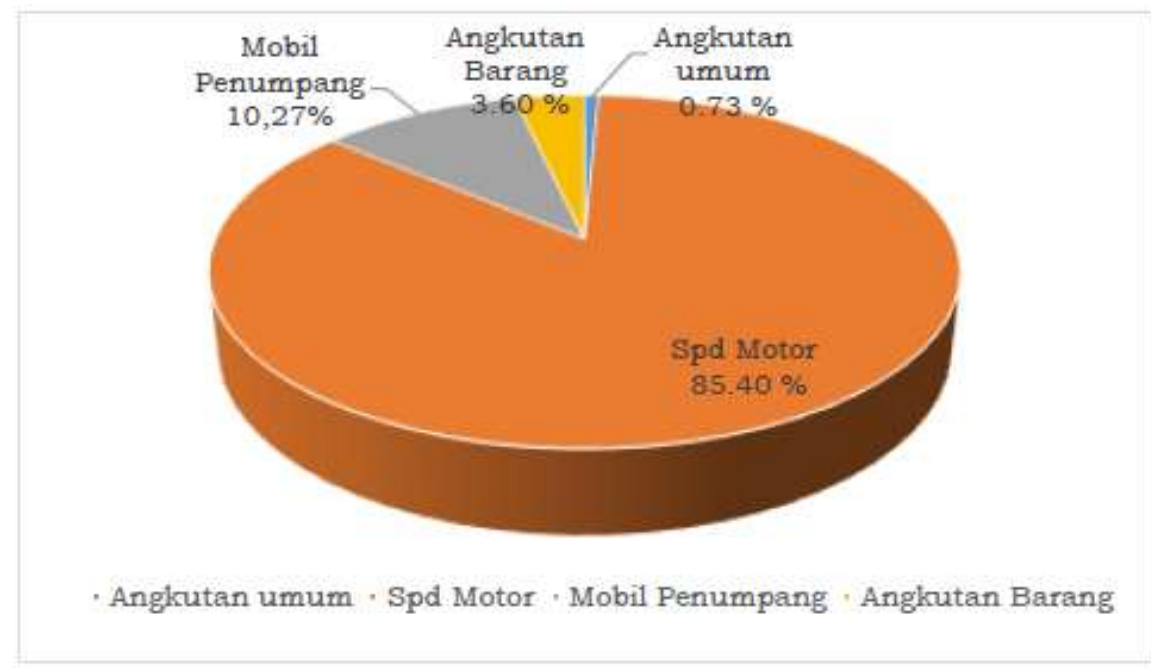

Gambar 3. Diagram Komposisi Pilihan Moda di Bali Th. 2019.

Perkembangan bangkitan perjalanan untuk jangka lima tahun ke depan, cenderung mengikuti trend pertumbuhan kendaraan bermotor Propinsi Bali, dengan tingkat pertumbuhan $5,812 \%$. Hasil prakiraan bangkitan perjalanan hingga Tahun 2024, dapat dilihat pada Tabel 4.

Tabel 4. Bangkitan dan Tarikan Perjalanan Harian di Bali Tahun 2024.

\begin{tabular}{ccc}
\hline & \multicolumn{2}{c}{$\mathbf{2 0 1 9}$} \\
zona & production & attraction \\
\hline 1 & $1,353,577$ & 947,504 \\
\hline 2 & 844,680 & $1,098,084$ \\
\hline 3 & 432,012 & 475,213 \\
4 & 128,680 & 141,548 \\
\hline 5 & 114,413 & 125,854 \\
6 & 200,932 & 221,025 \\
\hline 7 & 404,804 & 445,284 \\
8 & 190,108 & 209,119 \\
\hline 9 & 426,958 & 469,654 \\
\hline 10 & 18,524 & 17,814 \\
\hline 11 & 1,081 & 1,072 \\
\hline 12 & 1,997 & 1,888 \\
\hline 13 & 29,134 & 28,071 \\
\hline & $4,146,901$ & $4,182,130$ \\
\hline
\end{tabular}

\begin{tabular}{cc}
\hline \multicolumn{2}{c}{$\mathbf{2 0 2 4}$} \\
production & attraction \\
$1,795,385$ & $1,256,769$ \\
$1,120,384$ & $1,456,499$ \\
573,021 & 630,323 \\
170,681 & 187,749 \\
151,757 & 166,933 \\
266,516 & 293,168 \\
536,932 & 590,625 \\
252,159 & 277,375 \\
566,317 & 622,949 \\
24,571 & 23,629 \\
1,434 & 1,422 \\
2,649 & 2,504 \\
38,644 & 37,233 \\
$5,500,450$ & $5,547,179$ \\
\hline
\end{tabular}

\section{Pengembangan Moda Angkutan Umum Massal}

Pada kajian ini juga dicoba menskenariokan pengembangan moda angkutan umum yang baru untuk mengatasi permasalahan yang terjadi. Untuk menguji program moda baru dan mengetahui persepsi masyarakat baik itu pengguna yang captive maupun yang choice serta pengelola dilakukan survai 
interview secara sampling, melalui kuisioner terhadap moda yang akan dikembangkan.

Persepsi masyarakat tentang rencana adanya moda alternatif kereta api dari Denpasar ke semua Kabupaten atau sebaliknya, menunjukan mayoritas masyarakat setuju kalau seandainya ada rencana moda alternatif kereta api dari Denpasar kesemua Kabupaten di Bali dengan hasil survei setuju sebesar $56,89 \%$ dan sangat setuju sebesar $26,67 \%$ jadi total masyarakat yang setuju adalah $83,56 \%$. Masyarakat yang tidak setuju dan sangat tidak setuju total sebesar $8 \%$, rasa keberatan warga ini dengan berbagai alasan terutama perhitungan ganti rugi lahan untuk jalan rel dan dikhawatirkan akan merusak RTRW Bali.

Persepsi masyarakat tentang rencana adanya moda alternatif angkutan penyeberangan dari Denpasar ke semua Kabupaten atau sebaliknya, menunjukan mayoritas masyarakat setuju seandainya ada rencana moda alternatif angkutan penyeberangan dari Denpasar kesemua Kabupaten di Bali dengan hasil survei setuju sebesar $56,89 \%$ dan sangat setuju sebesar $32,44 \%$ jadi total masyarakat yang setuju adalah $89,33 \%$. Masyarakat yang tidak setuju sebesar $2,22 \%$.

\section{SIMPULAN}

Berdasarkan hasil survei dan analasis yang telah dilakukan pada kajian ini maka dapat diambil simpulan sebagai berikut.

1. Tingkat pertumbuhan kepemilikan kendaraan bermotor dan juga tingkat motorisasi cukup tinggi terutama di Denpasar dan Badung. Untuk itu harus dilakukan usaha untuk mengatasinya dengan merencanakan angkutan umum massal, road pricing, manajemen parkir dan usaha manajemen kebutuhan lalu lintas yang dilakukan secara simultan.

2.Distribusi perjalanan internal di Bali menunjukkan produksi perjalanan terbanyak adalah di Kota Denpasar dan Kuta. Sedangkan produksi dan tarikan perjalanan tertinggi di tiap kabupaten adalah Ubud di Gianyar, Bunutin dan Batur/Kintamani di Bangli, Gelgel dan Pasar Galiran di Klungkung, Pasar Amlapura di Karangasem, Kota Tabanan dan Tanah Lot di Tabanan, Terminal Banyuasri dan Seririt di Buleleng dan Gilimanuk di 
Jembrana. Berdasarkan data tersebut maka prasarana dan sarana menuju ke lokasi-lokasi tersebut mendapat prioritas untuk ditangani.

3. Distribusi perjalanan external memperlihatkan bahwa produksi dan tarikan perjalanan terbesar adalah di Bandara Ngurah Rai dan Pelabuhan Gilimanuk. Jadi kedua simpul tersebut harus dievaluasi kapasitasnya secara berkala dan akses prasarana maupun sarana di simpul tersebut harus menjadi prioritas

4. Pemilihan moda yang digunakan memperlihatkan bahwa lalu lintas di Bali adalah berbasis sepeda motor, maka harus direncanakan prasarana dan sarana berbasis sepeda motor untuk keselamatan berlalu lintas. Bila mengembangkan angkutan umum maka harus menggunakan aplikasi teknologi untuk menarik generasi muda menggunakannya.

5. Hasil prakiraan bangkitan dan tarikan perjalanan di Bali untuk lima tahun ke depan (Tahun 2024) menunjukkan jumlah yang besar, dengan tingkat pertumbuhan 5,812\%. Jadi perlu diantisipasi dengan pengembangan moda alternatif baru berbasis teknologi informasi seperti kereta api/LRT/ART dan angkutan penyeberangan dari Denpasar ke semua Kabupaten atau sebaliknya.

6.Persepsi masyarakat menunjukkan setuju dan sangat setuju lebih dari $83,56 \%$ untuk pengembangan moda alternatif kereta api/LRT/ART ke semua kabupaten di Bali dan sebaliknya dan yang tidak setuju $8 \%$.

7. Mayoritas masyarakat $89,33 \%$ setuju adanya rencana moda alternatif angkutan penyeberangan dari Denpasar kesemua Kabupaten di Bali. Moda ini dikembangkan dengan memanfaatkan pelabuhan penyeberangan seperti Benoa, Sanur, Jimbaran, Kedonganan yang bisa dimanfaatkan oleh masyarakat lokal maupun wisatawan untuk angkutan ke mall, café atau restaurant yang dituju.

Beberapa rekomendasi untuk upaya-upaya memberikan solusi tentang transportasi dan pengembangan program antara lain, 


\section{Supply Demand Approach}

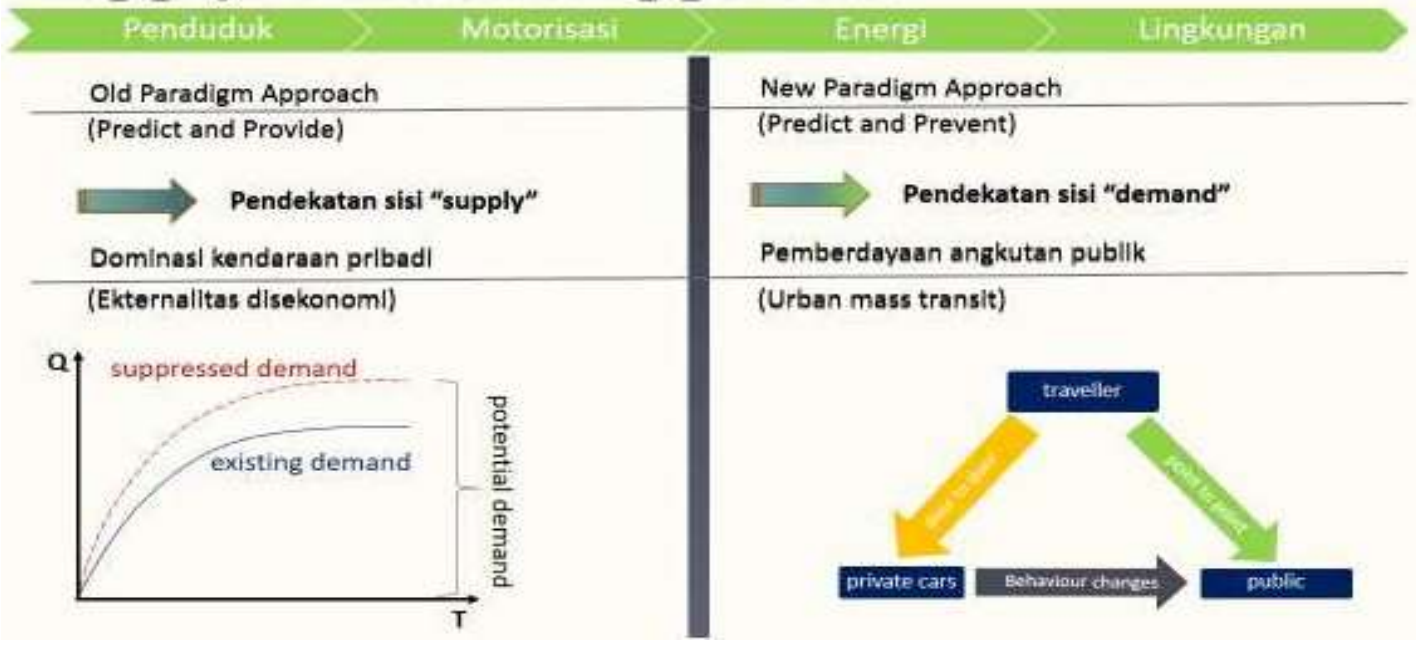

Gambar 4. Pendekatan Supply dan Demand.

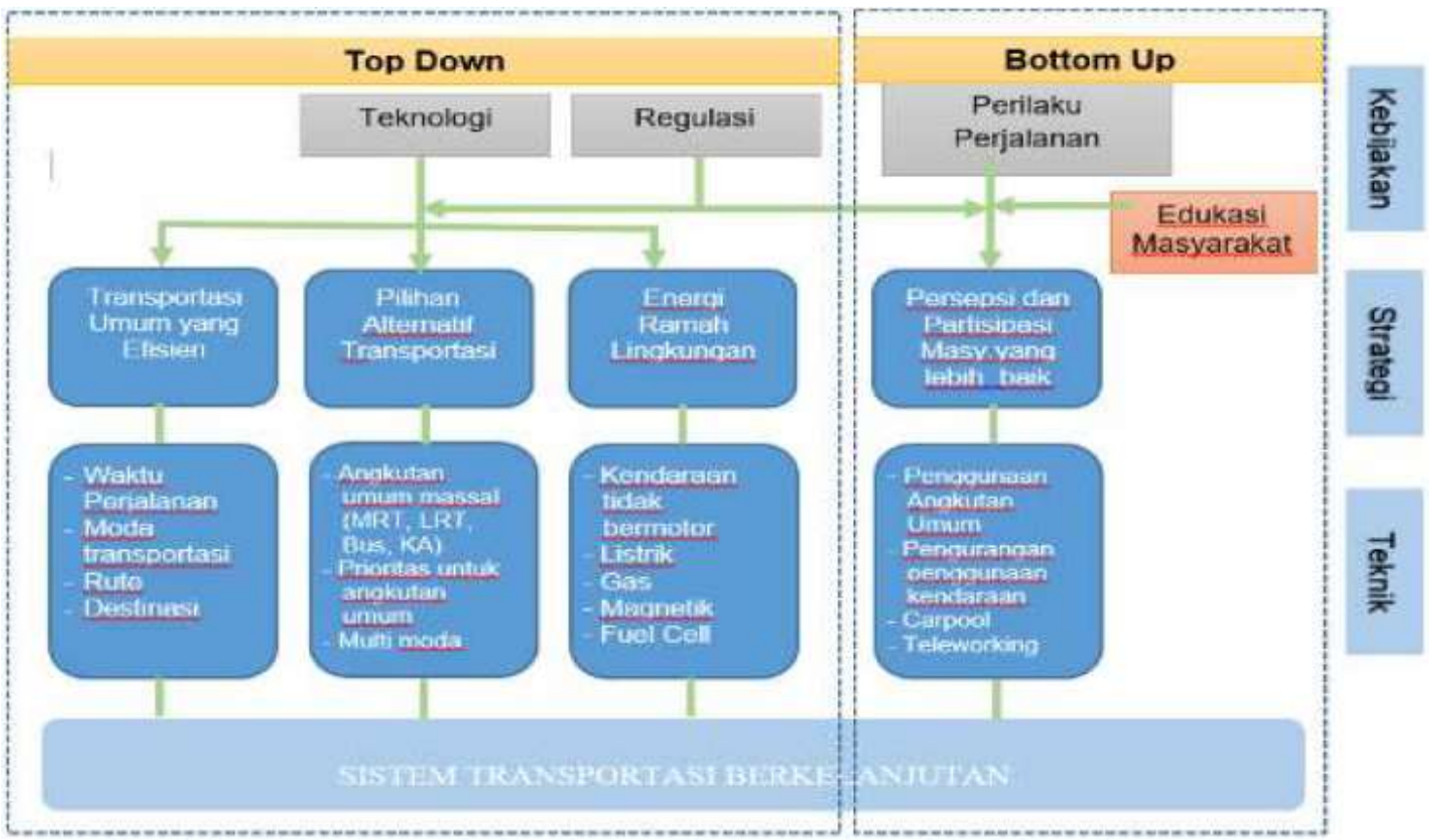

Gambar 5. Sistem Transportasi Berkelanjutan.

Penyediaan prasarana dan sarana direkomendasikan dirubah pendekatannya dengan paradigma baru yaitu pendekatan dari sisi demand dengan cara memprediksi dan mencegah (Predict and Prevent). Dengan pendekatan ini diharapkan pemberdayaan angkutan umum dan pelaku perjalanan dapat memahami perubahan karakter perjalanannya dari door to door menjadi point to point. Selengkapnya seperti digambarkan pada Gambar 
4. Kerangka program manajemen transportasi berkelanjutan yang dimaksud dapat dibagi menjadi dua yaitu Manajemen Top - Down dan bottom-up, dari segi kebijakan, strategi dan teknik seperti ditampilkan pada Gambar 5.

Sehubungan meningkatnya dengan cukup besar jumlah aktivitas perjalanan karena kegiatan ekonomi, pendidikan, pariwisata, dsb, maka perlu dikembangkan angkutan umum alternatif yang kapasitas angkutnya besar, untuk itu diusulkan :

a. Moda Alternatif Kereta Api/LRT/ART dari Denpasar ke semua kabupaten dan sebaliknya. Persepsi masyarakat yang setuju adalah 83,56\%. Prioritasnya adalah rute menuju ke Bandara Ngurah Rai.

b. Moda Alternatif Angkutan Penyeberangan dari Denpasar ke semua kabupaten dan sebaliknya, di mana hasil survai menunjukan mayoritas masyarakat (89,33\%) adalah setuju. Dapat dilakukan dengan memanfaatkan pelabuhan penyeberangan seperti Benoa, Sanur, Jimbaran, Kedonganan sebagai pelabuhan penyeberangan untuk masyarakat lokal maupun wisatawan untuk angkutan ke mall, café atau restaurant tujuannya seperti halnya yang dilakukan di Bangkok, Thailand.

Upaya-upaya yang dapat dilakukan dalam mengoptimalkan pelayanan di terminal Mengwi adalah :

a. Melaksanakan sistem pengelolaan fungsi ekonomi terminal, yang bisa dikembangkan dengan logika profit oriented.

b. Orientasi pokok pengelolaan Terminal Mengwi adalah menempatkan motivasi pelayanan sebagai tujuan utama dan motivasi pendapatan asli daerah (PAD) sebagai tujuan selanjutnya.

c. Pemerintah Daerah harus tegas dalam mengimplentasikan kebijakan sehubungan terjadinya dualisme fungsi terminal antara Ubung dan Mengwi. Pemerintah daerah harus tegas memberlakukan aturan dan sanksi bagi para pelanggar, agar penyelenggaraan fungsi terminal berjalan dengan baik

d. Menyediakan sarana transportasi umum di terminal yang memadai, dengan operasional angkutan umum lainnya dan juga perluasan rute bis Serbagita. untuk mempermudah akses transportasi publik ke Kota Denpasar dan sekitarnya, serta pembangunan jalan Beringkit - Sakah. 


\section{REFERENSI}

Badan Pusat Statistik Provinsi Bali, 2019, Bali Dalam Angka, Penerbit BPS Provinsi Bali

Budi Sitorus, 2010, Kajian Pembenahan Angkutan Massal untuk Mengurangi Kemacetan Lalu Lintas di DKI Jakarta, Bidag Transportasi Darat-Badan Litbang Perhubungan

Dinas Perhubungan Provinsi Bali, Profil Perhubungan Bali Tahun 2018

Eka Tamar A, Pengembangan Angkutan Umum di Kawasan Sarbagita, 2014, Jurnal IImiah Elektronik Infrastruktur Teknik Sipil, Prodi Teknik Sipil, Univrsitas Udayana

Hermawati P., Adisasmita S.A., Ramli M.I., Sumarni H., 2017 (a), Perancangan Instrumen Kuisioner Perilaku Perjalanan Wisatawan Mancanegara di Bali, LOGIC (Jurnal Rancang Bangun dan Teknologi), Vol.17 No.1, Maret

Hermawati P., Adisasmita S.A., Ramli M.I., Sumarni H., 2017 (c), The Travel Behaviors of Foreign Tourist in Bali-Indonesia, Proceeding of the $12^{\text {th }}$ International Conference of Eastern Asia Society for Transportation Studies (EASTS), Vietnam, 2017

Hermawati P., Adisasmita S.A., Ramli M.I., Sumarni H., 2016, A Study On The Characteristic of Tourists Trip Distribution in Bali, Indonesia, Proceeding of The International Seminar on Infrastructure Development (ISID) 2016, Makassar. 